DOI: $\underline{10.17805 / g g z .2019 .3 .6}$

\title{
Возвращаясь к Хельсинской декларации: этическая регламентация сбора генетических данных
}

\author{
С. Ю. Шевченко
}

Институт философии РАН;

Российский национальный исследовательский

медииинский университет имени Н. И. Пирогова, г. Москва

В статье рассматриваются проблемы биоэтической регламентации сбора, хранения, обработки и разглашения генетических данных. В качестве примера использована практика генетического тестирования, не требующая участия врача-генетика (direct-to-consumer genetic testing), поскольку она связана с наибольшими этико-правовыми рисками. Многие обозначенные в литературе риски этой практики могут быть релевантны и для других процедур сбора генетических данных. Необходимость их минимизации актуализирует различение между терапевтическими и нетерапевтическими биомедицинскими исследованиями. Это различение служило одной из кониептуальных основ ранних версий (подготовленных до 2000 года) Хельсинской декларации Всемирной медицинской ассочиачии.

Показано, что это различение было изъято из текста декларачии, потому что уже существовали образиь более тонкого регулирования биомедицинских исследований, принятые на начиональном уровне. В их основу было положено то же самое различение, применявшееся к отдельным процедурам и манипуляциям. В этой связи это различение может стать ориентиром как внутренней регуляции биомедицинских практик, утверждаемых локальным этическим комитетом, так и ориентиром для правовой регламентации сбора, хранения, обработки и разглашения генетических данных.

В качестве образиа внешнего биоэтического регулирования этих практик приводится трехступенчатая система этического сопровождения биомедицинских исследований, используемая в Евросоюзе. На первом из этапов самая общая форма заявки на поддержку исследования проходит так называемый «генетический скрининг». На втором - полный дизайн исследований подвергается тщательному анализу экспертной панелью, состоящей не менее чем из 5-6 специалистов по биоэтике. На третьем этапе, в ходе

\footnotetext{
* Исследование выполнено при финансовой поддержке РФФИ в рамках научного проекта № 18-29-14100.

The research was carried out with financial support from the Russian Foundation for Basic Research within the framework of the project No. 18-29-14100.
} 
реализации утвержденного дизайна исследования оно проходит регулярный этический аудит.

Ключевые слова: этический комитет; генетические данные; информированное согласие; биобанкинг; биоэтика; Хельсинская декларация

\title{
Declaration of Helsinki Revisited: Ethical Regulation of Genetic Data Collection
}

\author{
S. Yu. Shevchenko \\ Institute of Philosophy, Russian Academy of Sciences; \\ Pirogov Russian National Research Medical University, Moscow
}

The article deals with the problems of bioethical regulation of collection, storage, processing and disclosure of genetic data. Direct-to-consumer genetic testing is used as an example, because it is related to the greatest ethical and legal risks. Many of the risks of this practice that have been identified in the professional literature may also be relevant for other procedures of genetic data collection. The need to minimize these risks actualizes the distinction between therapeutic and non-therapeutic biomedical research. This distinction served as one of the conceptual foundations of the earlier versions (prepared before 2000) of the Declaration of Helsinki of the World Medical Association.

It is shown that this distinction was removed from the text of the declaration, because there had already been models of more precise regulation of biomedical research adopted at the national level. They were based on the very same distinction applied to individual procedures and manipulations. In this regard, this distinction can be a guideline for both the internal regulation of biomedical practices, which are approved by the local ethical committee, and for the legal regulation of collection, storage, processing and disclosure of genetic data.

As a model of external bioethical regulation of these practices, a three-step system of ethical assessment for biomedical research used in the European Union is presented. At the first stage, the most general form of a request for research support is the so-called "genetic screening". On the second stage, the full research design is thoroughly analyzed by an expert panel consisting of no less than 5-6 bioethics specialists. At the third stage, during the implementation of the approved research design, it undergoes a regular ethical audit.

Keywords: ethical committee; genetic data; informed consent; biobanking; bioethics; Declaration of Helsinki

\section{ВВЕДЕНИЕ}

Сегодня этико-правовые вызовы, связанные с развитием геномных технологий, являются одной из основных проблем широкого спектра гумани- 
тарных дисциплин от психологии и социологии до политической философии и медицинского права. Наиболее пристальное внимание широкой общественности в последние годы приковано к вопросам регулирования редактирования генома - в частности, применения технологии CRISP-Cas9. При этом значительная часть усилий по биоэтическому и законодательному регулированию направлена на более широко распространенные практики сбора генетических образцов, обработки и разглашения генетической информации.

Во многом такие усилия связаны с регламентацией деятельности биобанков, хранящих «большие генетические данные». В России этот вектор этико-правовой работы связан с формированием популяционного биобанка, получившего неофициальное название «Ноев ковчег» в рамках проекта, осуществляемого МГУ. В Китае регламентация связана с обязательным лицензированием биобанков и иных коллекций биологических образцов (Cyranoski, 2019: Электронный ресурс).

Помимо собственно деятельности биобанков в США и странах Европейского союза серьезной регуляторной проблемой являются и практики генетического тестирования, не требующие участия врача или генетического консультанта — так называемое direct-to-consumer (DTC) генетическое тестирование. В рамках этой процедуры клиент отправляет по почте биологический образец, содержащий его ДНК (обычно слюну), в биотехнологическую лабораторию, оплачивая ей услугу по расшифровке и интерпретации его генетической информации. С результатами этой работы клиент знакомится самостоятельно, обычно информация поступает ему на домашний адрес или электронную почту. DTC тестирование не легализовано в России, однако рассмотрение истории этой практики и связанных с ней биоэтических казусов способно внести важные уточнения в дискуссии об этико-правовом регулировании сбора, обработки и разглашения генетических и геномных данных. В первую очередь они касаются важности типологизации научных геномных исследований в зависимости от их целей и задач.

Исходя из этого, в первом разделе статьи будут намечены несколько биоэтических проблем, связанных с практиками DTC генетического тестирования. Во втором - приведен биоэтический казус, связанный с этими практиками. В третьем разделе в свете указанных проблем будут рассмотрены разные редакции ключевого международного биоэтического документа Хельсинской декларации Всемирной медицинской ассоциации. Четвертый раздел будет посвящен применению указанных различений собственно к процедурам сбора генетического материала. Итоги, посвященные регламентации научных и клинических практик в целом, будут подведены в пятом разделе статьи. 


\section{DТС ГЕНЕТИЧЕСКОЕ ТЕСТИРОВАНИЕ: МОТИВЫ ЗАПРЕТА И СТРАТЕГИИ ЛЕГИТИМАЦИИ}

Пик энтузиазма в отношении DTC генетического тестирования приходится на конец 2000-х — начало 2010-х гг. В 2013 г. наиболее значимый рынок этой услуги - американский - приостановил свою деятельность в связи с решением регулятора FDA (Food and Drug Administration - Управление по санитарному надзору за качеством пищевых продуктов и медикаментов). В 2017 г. он разрешил биотехнологической компании 23andMe возобновить DTC-тестирование, но с существенными ограничениями - доступные клиенту результату могли касаться только 10 нозологий, большинство из которых редкие.

При этом еще до 2013 г. многие профессиональные медицинские организации США требовали запрета DTC генетического тестирования. А авторы опубликованного в 2012 г. систематического обзора 314 публикаций, касающихся регламентации этой практики, пришли к выводу, что большинство из рассматриваемых ими текстов посвящено обсуждению недостатков и потенциальных рисков тестирования (Skirton et al., 2012). Ограничения, действующие в США с 2017 г., способствовали снижению лишь медицинских рисков, при этом многие этико-правовые проблемы стали лишь актуальнее за прошедшие с момента публикации обзора семь лет. Так, по-прежнему, остается не до конца определенной судьба накапливаемых биотехнологическими компаниями генетических данных людей. При этом соглашающийся на DTC генетическое тестирование обычно никак не может повлиять на способы распоряжения с ними - из-за неспособности отозвать свое согласие на распоряжение генетической информацией. Неясно и то, что будет происходить с данными при продаже или поглощении этих компаний другими - такая передача права распоряжаться генетическими данными другому субъекту может противоречить интересам человека, однажды согласившегося на генетическое тестирование (Borry, 2010). В то же время благодаря развитию технологий обработки «больших данных» с каждым годом растет риск реанонимизации людей, прошедших DTC генетическое тестирование.

Во многом перечисленные проблемы актуальны и для существующих в легальном поле на территории России практик сбора, обработки и разглашения генетических данных. В этой связи для дальнейшего рассмотрения будет значимо вкратце очертить стратегию, которой пользовались биотехнологические компании для защиты от регуляторного давления в начале 2010-х гг. Так, еще в 2011 г. - т. е. до запрета FDA - уже упомянутая компания 23andMe декларировала, что DTC генетическое тестирование не является медицинской услугой. Его предлагалось воспринимать как образовательную 
практику или возможность поучаствовать в большом популяционном генетическом исследовании (Tutton, Prainsack, 2011).

Такая линия защиты связана с несколькими факторами: во-первых, FDA не регламентирует образовательные и исследовательские практики; вовторых, как мы покажем ниже, даже компетентные клиенты компании воспринимают услугу как медицинскую. При этом не было четкого доказательного обоснования приводимых компанией оценок наследственных рисков, тем более не предлагала компания и стратегии их минимизации.

Вместе с тем Хельсинская декларация ВМА в редакции 1996 года и в более ранних редакциях проводит четкое разграничения между медицинскими исследованиями и исследованиями, ставящими целью лишь приращение научного знания, а не помощь конкретным пациентам. При этом, в третьем разделе статьи мы подробнее рассмотрим, почему этическая регламентация сбора генетических данных в рамках нетерапевтических процедур должна быть более жесткой. Однако перед этим, в следующем разделе статьи, мы рассмотрим DTC генетическое тестирование как наиболее рискогенную (с этико-правовой и медицинской точек зрения) практику сбора, обработки и разглашения генетической информации.

\section{DТС ГЕНЕТИЧЕСКОЕ ТЕСТИРОВАНИЕ: \\ КАЗУС ХОРОШО ИНФОРМИРОВАННОГО КЛИЕНТА}

Американский социолог медицины и специалист по биоэтике Донна Месснер в 2011 г. представила публике одну из наиболее проблематичных ситуаций, которые могут возникнуть в контексте DTC генетического тестирования (Messner, 2011). При этом в современных американских правовых реалиях ее повторение невозможно из-за ограничения списка заболеваний, наследственные риски развития которых устанавливаются во время тестирования. Однако этот случай наиболее полным образом раскрывает этические риски данной практики и коллизии, возникающие из-за различия в ее восприятии биотехнологическими компаниями, их (даже хорошо информированными) клиентами, а также медицинским сообществом.

Джош, мужчина старше 40 лет, был сотрудником биомедицинской компании, которая предлагала своим работникам бесплатно пройти DTC генетическое тестирование в компании-партнере. Джош знал о своей семейной истории диабета II типа, поэтому согласился на это предложение. Он профессионально разбирался в биотехнологических особенностях процедуры, имел достаточно глубокие (но не профессиональные) знания в области медицинской генетики. Эти знания, как он считал, смогут помочь ему самостоятельно интерпретировать результаты теста. Джош дал информированное согласие на сайте компании-партнера и отправил им образец слюны, содержащий его 
ДНК. Пришедшие результаты гласили, что его риск заболеть диабетом II типа не выше популяционного, а вот риск раннего развития болезни Альцгеймера значительно выше. Джош обратился в компанию за генетической консультацией, в рамках которой ему дали рутинный совет вести здоровый образ жизни, больше времени уделять физической активности и есть больше овощей. Семейный врач Джоша вообще не знал, как интерпретировать результаты теста.

При этом даже поиск в научных базах данных лишь усилил неопределенность, с которой столкнулся Джош. Согласно полученным им результатам вероятность развития болезни Альцгеймера составляла $69 \%$, в то время как крупное популяционное исследование связывало обнаруженную у Джоша генетическую вариацию с риском в $91 \%$.

Итак, мы видим, что хорошо информированный клиент биотехнологической компании получил результаты касательно тех рисков, о которых он не рассчитывал узнать, давая согласие на процедуру. Биотехнологическая компания декларировала принадлежность своих услуг к образовательным, помогающим клиенту сделать информированный выбор образа жизни. Ее клиент не проводил различия между своими ожиданиями получить биомедицинскую информацию, с которой впоследствии должны иметь дело консультант и семейный врач, и намерением самостоятельно ее интерпретировать.

Рутинное медицинское генетическое тестирование предполагает, что пациент, соглашающийся на него, участвует как минимум в двух продолжительных консультациях. В рамках первой определяется необходимость генетического тестирования, а также спектр тех вопросов, на которые позволят дать ответ его результаты. В рамках второго они будут интерпретированы. Такой способ принятия решения в значительной степени позволяет избежать рисков, связанных с информированием пациента о его / ее генетических рисках. Комментируя изложенный выше казус, биоэтик Джессика Майнор называет центральным элементом принятия информированного решения о генетическом тестировании именно наличие двух генетических консультаций (до и после тестирования) (Minor, 2015: 185-190). Кроме того, полученные в рамках медико-генетического исследования данные будут более специфичны, поэтому несколько снижаются и этико-правовые риски, связанные с их разглашением третьим лицам, вопреки воле распоряжающегося ими субъекта.

ХЕЛЬСИНСКАЯ ДЕКЛАРАЦИЯ:

\section{ЦЕЛИ ИССЛЕДОВАНИЯ И ХАРАКТЕР ЕГО КОМПОНЕНТОВ}

В данной статье предлагается использовать различение терапевтических и нетерапевтических целей исследования, введенное в первой редакции 
Хельсинской декларации Всемирной медицинской ассоциации в 1964 г. и изъятое оттуда в рамках подготовки пятой версии документа, опубликованной в 2000 г. ${ }^{1}$ Подчеркнутое во Введении и отраженное в самой структуре декларации это разделение касалось исследовательских практик и было призвано дополнить Нюрнбергский кодекс 1947 года, сделав его принципы более конкретными и практически применимыми. В соответствии с введенной дистинкцией, эксперименты, прямо направленные на то, чтобы приносить биомедицинскую пользу своим участникам, регулировались более мягко по сравнению с нетерапевтическими исследованиями, т. е. проводимыми с целью накопления научного знания. Привлечение участников в терапевтические, т. е. клинические, исследования требовало более простой процедуры получения информированного согласия (Carlson, Boyd, Webb, 2004).

Во многом использование этого различения было обусловлено контекстом разработки Нюрнбергского кодекса - нацистские врачи, участвовавшие в экспериментах над узниками концлагерей, в рамках судебного процесса апеллировали в том числе к научной ценности полученных ими результатов. Однако позднее это различие между терапевтическими и нетерапевтическими экспериментами подверглась критике, которая относится скорее к устоявшейся в 1970-1990-х гг. практики использования этой дистинкции в рамках регламентации биомедицинских исследований.

Однако эта критика касалась не столько правомерности самого различения целей исследовательских практик, сколько применения этого различения для их этического регулирования. Одним из главных оснований в пользу изъятия этой дистинкции из текста документа была аргументация американского врача Роберта Левина. В рамках обсуждения готовящейся новой версии декларации в 1999 г. в авторитетном профессиональном издании - «Медицинском журнале Новой Англии» (The New England Journal of Medicine) Левин пишет, что современные биомедицинские исследования зачастую имеют сложный и многокомпонентный дизайн, поэтому четко разделять их на две предлагаемые документом категории проблематично. Необходимо применять это различение к компонентам исследования, конкретным действиям и процедурам, что и происходит в США. Еще в 1970-х гг. в США Национальная комиссия по защите людей, участвующих в биомедицинских и поведенческих исследованиях (National Commission for the Protection of Hu-

\footnotetext{
${ }^{1}$ В версии 1996 года эта дистинкция обозначена во самом начале текста декларации следующим образом: «В области биомедицинских исследований необходимо признать принципиальное различие между медицинскими исследованиями, целью которых является в первую очередь диагностика или лечение, и медицинскими исследованиями, основная цель которых чисто научная, и которые не имеют непосредственного диагностического или терапевтического значения для лиц, вовлеченных в исследование».
} 
man Subjects of Biomedical and Behavioral Research), приняла соответствующие рекомендации, которые затем стали основанием государственной политики в сфере регулирования таких исследований (Levine, 1999). В таком контексте более грубый регуляторный инструмент совершенно справедливо кажется Левину излишним. Разделение самих исследований всего на две категории не нужно, так как каждый их компонент оценивается и регламентируется как терапевтический или нетерапевтический. При этом последние регулируются более жестко и привлекают более пристальное внимание этических комитетов и федеральных чиновников. Устоявшиеся практики такого точечного регулирования позволяют более специфично оценивать и минимизировать этико-правовые риски отдельных процедур

\section{ФОРМА ДОБРОВОЛЬНОГО СОГЛАСИЯ И РЕГЛАМЕНТАЦИЯ КОМПОНЕНТОВ ИССЛЕДОВАНИЯ}

Сбор генетического материала, несомненно, является важной процедурой, терапевтический или нетерапевтический характер которой может служить основанием для той или иной формы ее регулирования. В рамках социогуманитарного сопровождения развития биобанка при МГУ имени М. В. Ломоносова были намечены основные биоэтические проблемы, которые необходимо урегулировать перед началом сбора биологического материала, в том числе в целях получения обработки генетических данных человека. Первая из них касается широты спектра возможных манипуляций с биологическим материалом и генетическими данными, на которые может быть дано одномоментное согласие. При этом в качестве наиболее этически благоприятной возможности рассматривается получение временного согласия на манипуляции с биоматериалом и «извлеченной» из него информацией. Однако сам информационный листок выдаваемый донору биоматериала содержит лишь гарантию того, что данные будут анонимизированы методом двойного шифрования. Также указано, что биобанк не будет передавать любой фрагмент данных другим биобанкам без дополнительного испрошенного согласия донора (Брызгалина и др., 2018: 176-177). При этом в информационном листке содержится лишь общая формулировка о важности данных, хранящихся в биобанке для проведения биологических и медицинских исследований. Однако в форме добровольного согласия не содержится информации о возможных типах исследований, в рамках которых будут использованы генетические и персональные данные донора. Таким образом, донор лишен возможности ограничить использование своего генетического материала. Например, донор мог бы по-разному оценить возможность использования своих генетических данных в рамках поиска генетических предикторов заболеваний и в рамках популяционно-генетических исследований, направлен- 
ных на реконструкцию этногенеза. При этом чем дальше возможное применение результатов исследований от медицинского, тем более конкретными должны быть формулировки в бланке информированного согласия.

Более мягкое регулирование использования генетических данных в медицинских исследованиях обеспечивается не только социально-значимым характером таких исследований, но и решением второй важной этикоправовой проблемы, предложенным группой биоэтиков из МГУ имени М. В. Ломоносова. Эта проблема касается обратной связи с донором по поводу релевантных медицинских результатов исследования биоматериалов. Формой информированного согласия предусмотрена возможность позволить или не позволить осуществить такую связь в будущем. В информационном листке сказано, что она может быть осуществлена, если в геноме донора будут обнаружены связанные с рисками для здоровья особенности генома. Однако подобное дополнительное информирование обо всех рисках чревато возникновением психологически и социально напряженных ситуаций подобных той, в которой оказался Джош, герой приведенного выше казуса. Вероятно, доноры могли бы давать согласие на информирование только о предотвратимых рисках для здоровья. Предотвратимый характер рисков мог бы быть отражен в информационном листке, выдаваемом донору.

Итак, регламентация процедуры сбора, обработки и разглашения генетической информации может осуществляться по-разному в рамках проведения медицинских исследований, и тогда донор может выбрать вариант с обратной связью, и в рамках иных, нетерапевтических, исследований. В последнем случае форма информированного согласия может предусматривать большее число ограничений, быть более конкретной или даже предполагать согласие на использование данных в течение ограниченного срока.

\section{ЭТИЧЕСКОЕ СОПРОВОЖДЕНИЕ И РЕГЛАМЕНТАЦИЯ КЛИНИЧЕСКИХ И ИССЛЕДОВАТЕЛЬСКИХ ПРАКТИК В ЦЕЛОМ}

Форма добровольного согласия позволяет создать информационную среду, благоприятствующую принятию донором взвешенного решения касательно разных компонентов сбора, обработки и разглашения генетических данных. Описанная Левиным американская практика биоэтической оценки отдельных процедур и манипуляций, происходящих в ходе исследования, позволяет выделить эти компоненты. Однако такое внимание к элементам исследовательских практик не исключает возможности их целостной этической оценки и этического сопровождения.

Клинические практики в отношении их отдельных элементов уже достаточно четко регламентированы, а их цель по определению заключается в том, чтобы принести благо конкретному пациенту. При этом вопрос если не о 
целях, то о социальных и этико-правовых последствиях исследовательских практик до сих пор актуален с регуляторной точки зрения. Он является одним из краеугольных камней этического сопровождения исследований, получающих поддержку Евросоюза.

Этот механизм зачастую приводится как образец работы этических комитетов даже при обсуждении таких острых проблем как регламентация редактирования генома человека. Этическое сопровождение предполагает три этапа (Hirsch, Iphofen, Koporc, 2019). На первом из них самая общая форма заявки на поддержку исследования проходит так называемый «генетический скрининг». В анонимизированной форме она получает рецензию двух независимых экспертов-биоэтиков. Они дают заключение о целях и возможных социальных, этико-правовых, психологических последствиях и рисках исследования.

Те проекты, которые определены как «этически чувствительные» (ethically sensitive) должны в рамках второго этапа предоставить детальный дизайн исследования (и формы добровольного согласия) для рассмотрения экспертной панелью, состоящей не менее чем из 5-6 независимых специалистов по биоэтике. Если на этом этапе проект будет утвержден, то по завершении каждого года исследовательского проекта он подвергается этическому аудиту. По результатам третьего этапа сопровождения дизайн исследования может быть откорректирован, а сам проект - приостановлен.

\section{ЗАКЛЮЧЕНИЕ}

Таким образом, эта трехэтапная модель предусматривает сочетание деятельности «внутреннего» этического комитета, утверждающего дизайн исследования, и внешнего биоэтического контроля и сопровождения, способного внести реальные коррективы в решения «внутреннего» комитета. При этом этической оценке подвергается как характер отдельных процедур сначала внутренним комитетом, а затем независимой экспертной панелью так и общие последствия исследования в рамках этического скрининга и работы экспертной панели.

\section{СПИСОК ЛИТЕРАТУРЫ}

Брызгалина, Е. В. и др. (2018) Биобанкинг: социально-гуманитарные аспекты / Е. В. Брызгалина, К. Ю. Аласания, Т. А. Вархотов, С. М. Гавриленко, А. Л. Рыжов, Е. М. Шкомова. М. : Изд-во МГУ. 232 с.

Borry, P. (2010) Statement of the ESHG on direct-to-consumer genetic testing for health-related purposes // European Journal of Human Genetics. Vol. 18. No. 12. P. 1271-1273. DOI: 10.1038/ejhg.2010.129 
Carlson, R. V., Boyd, K. M., Webb, D. J. (2004) The revision of the Declaration of Helsinki: Past, present and future // British Journal of Clinical Pharmacology. Vol. 57. No. 6. P. 695-713. DOI: 10.1111/j.1365-2125.2004.02103.x

Cyranoski, D. (2019) China announces hefty fines for unauthorized collection of DNA [Электронный ресурс] // Nature. June 14. URL: https://www.nature. com/articles/d41586-019-01868-2 [архивировано в WaybackMachine] (дата обращения: 17.06.2019).

Hirsch, F., Iphofen, R., Koporc, Z. (2019) Ethics assessment in research proposals adopting CRISPR technology // Biochemia Medica. Vol. 29. No. 2. URL: https://biochemia-medica.com/en/journal/29/2/10.11613/BM.2019.020202/ fullArticle [архивировано в WaybackMachine] (дата обращения: 17.06.2019). DOI: $10.11613 /$ BM.2019.020202

Levine, J. P. (1999) The need to revise the Declaration of Helsinki // The New England Journal of Medicine. Vol. 341. No. 7. P. 531-534. DOI: 10.1056/ NEJM199908123410713

Messner, D. (2011) Informed choice in direct-to-consumer genetic testing for Alzheimer and other diseases: Lessons from two cases // New Genetics in Sociology. Vol. 30. No. 1. P. 59-72. DOI: 10.1080/14636778.2011.552300

Minor, J. (2015) Informed consent in predictive genetic testing: A revised model. Cham ; Heidelberg ; N. Y. ; Dordrecht ; L. : Springer. vii, 232 p.

Skirton, H. et al. (2012) Direct to consumer genetic testing: A systematic review of position statements, policies and recommendations / H. Skirton, L. Goldsmith, L. Jackson, A. O’Connor // Clinical Genetics. Vol. 82. No. 3. P. 210-218. DOI: $10.1111 / \mathrm{j} .1399-0004.2012 .01863 . \mathrm{x}$

Tutton, R., Prainsack, B. (2011) Enterprising or altruistic selves? Making up research subjects in genetics research // Sociology of Health \& Illness. Vol. 33. No. 7. P. 1081-1095. DOI: $\underline{10.1111 / j .1467-9566.2011 .01348 . x}$

Дата поступления: 20.06.2019 г.

\section{REFERENCES}

Bryzgalina, E. V. et al. (2018) Biobanking: sotsial'no-gumanitarnye aspekty [Biobanking: Social and humanitarian aspects] / E. V. Bryzgalina, K. Y. Alasaniya, T. A. Varkhotov, S. M. Gavrilenko, A. L. Ryzhov and E. M. Shkomova. Moscow : Moscow State University Publ. 232 p. (In Russ.).

Borry, P. (2010) Statement of the ESHG on direct-to-consumer genetic testing for health-related purposes. European Journal of Human Genetics, vol. 18, no. 12, pp. 1271-1273. DOI: 10.1038/ejhg.2010.129 
Carlson, R. V., Boyd, K. M. and Webb, D. J. (2004) The revision of the Declaration of Helsinki: Past, present and future. British Journal of Clinical Pharmacology, vol. 57, no. 6, pp. 695-713. DOI: 10.1111/j.1365-2125.2004.02103.x

Cyranoski, D. (2019) China announces hefty fines for unauthorized collection of DNA. Nature, June 14. [online] Available at: https://www.nature.com/ articles/d41586-019-01868-2 [archived in WaybackMachine] (accessed 17.06. 2019).

Hirsch, F., Iphofen, R. and Koporc, Z. (2019) Ethics assessment in research proposals adopting CRISPR technology. Biochemia Medica, vol. 29, no. 2. [online] Available at: https://biochemia-medica.com/en/journal/29/2/10.11613/ BM.2019.020202/fullArticle [архивировано в WaybackMachine] (accessed 17. 06.2019). DOI: $10.11613 /$ BM.2019.020202

Levine, J. P. (1999) The need to revise the Declaration of Helsinki. The New England Journal of Medicine, vol. 341, no. 7, pp. 531-534. DOI: 10.1056/NEJM 199908123410713

Messner, D. (2011) Informed choice in direct-to-consumer genetic testing for Alzheimer and other diseases: Lessons from two cases. New Genetics in Sociology, vol. 30, no. 1, pp. 59-72. DOI: 10.1080/14636778.2011.552300

Minor, J. (2015) Informed consent in predictive genetic testing: A revised model. Cham ; Heidelberg ; New York ; Dordrecht ; London : Springer. vii, 232 p.

Skirton, H., et al. (2012) Direct to consumer genetic testing: A systematic review of position statements, policies and recommendations / H. Skirton, L. Goldsmith, L. Jackson and A. O’Connor. Clinical Genetics, vol. 82, no. 3, pp. 210-218. DOI: 10.1111/j.1399-0004.2012.01863.x

Tutton, R. and Prainsack, B. (2011) Enterprising or altruistic selves? Making up research subjects in genetics research. Sociology of Health \& Illness, vol. 33, No. 7, pp. 1081-1095. DOI: 10.1111/j.1467-9566.2011.01348.X

Submission date: 20.06.2019.

Шевченко Сергей Юрьевич - научный сотрудник сектора гуманитарных экспертиз и биоэтики Института философии Российской академии наук; преподаватель кафедры биоэтики Российского национального исследовательского медицинского университета имени Н. И. Пирогова. Адрес: 109240, Россия, г. Москва, ул. Гончарная, д. 12, стр. 1. Тел.: +7 (495) 697-90-67. Эл. адрес: simurg87@list.ru

Shevchenko Sergei Yurievich, Researcher, Department of Humanitarian Expertise and Bioethics, Institute of Philosophy, Russian Academy of Sciences; Lecturer, Department of Bioethics, Pirogov Russian National Research Medical Uni- 
versity. Postal address: Bldg. 1, 12 Goncharnaya St., 109240 Moscow, Russian Federation. Tel.: +7 (495) 697-90-67. E-mail: simurg87@list.ru

ORCID: 0000-0002-7935-3444

Researcher ID: F-5320-2018

Scopus Author ID: 57192993265

SPIN-код: 2783-6006

Для цитирования:

Шевченко С. Ю. Возвращаясь к Хельсинской декларации: этическая регламентация сбора генетических данных [Электронный ресурс] // Горизонты гуманитарного знания. 2019. № 3. C. 69-81. URL: http://journals.mosgu.ru/ ggz/article/view/1046 (дата обращения: дд.мм.гггг). DOI: 10.17805/ggz.2019.3.6 